\title{
Copyright term extension and orphan works
}

\author{
Hal R. Varian* \\ January 2006 \\ Revised: August 29, 2006
}

\begin{abstract}
I examine three recent topics in copyright policy from an economic perspective: (1) term extensions, (2) the orphan works problem, and (3) mass digitization projects. This paper was prepared for the seminar on "Information, Intellectual Property, and Economic Welfare. The legacy of Kenneth Arrow and Richard Nelson" held at Turin, Italy, May 15-16, 2006, and sponsored by the Fondazione Luigi Einaudi. It will appear in the Industrial and Corporate Change in Spring 2007.
\end{abstract}

\footnotetext{
${ }^{*}$ Email contact: hal@sims .berkeley.edu
} 
Most economic writing about intellectual property has focused on patents, with other forms of intellectual property being relatively neglected. Recently, however, there has been a growing interest in copyright. See, for example, the Society for Economic Research on Copyright Issues web page (http: //www.serci.org), the recent compilation of articles by Landes and Posner [2003] and the recent review articles by Varian [2005a] and Watt [2004].

One can compare copyright and patents along three dimensions: length, width and height. The term (length) of a patent is 20 years, while the term of a copyright in the United States is the life of the author plus 70 years. The breadth of coverage (width) of a patent depends on the claims asserted. Copyright, by comparison, is very narrow, covering only the expression of ideas, not the ideas themselves. The standard of novelty (height), is also quite different. There is an explicit requirement of non-obviousness for patents, but there is no such requirement for copyright.

Indeed, virtually any creative work is automatically copyrighted at the time of its creation. Furthermore, there is no requirement that works be registered in order to be copyrighted. Registration offers a few advantages in case one needs to sue for infringement, but these are relatively minor. ${ }^{1}$ On the other hand the cost of registration (\$30) is relatively minor as well. Things are quite different for patents, where registration is required and can cost several thousand dollars.

Copyright has become a significant public policy issue in recent years due to the dramatic growth of the Internet and, particularly,the World Wide Web. It has been said that "Freedom of the press belongs to those who own one." But now, in a real sense, virtually everyone "owns one." Digital technology has made the production and distribution of works phenomenally inexpensive.

The reproduction, storage, and dissemination of text, sound, images,

\footnotetext{
${ }^{1}$ See http://www. copyright.gov/circs/circ1.html \\#cr for a list of the benefits and costs of registration.
} 
video costs fractions of a cent. Nordhaus [2002] estimates that the cost of computation has fallen by a factor of 1 to 5 trillion since 1900. Not surprisingly, this dramatic reduction in cost has led to an equally dramatic increase in output. Lyman and Varian $[2000,2003]$ estimate that in 2000 about 1.5 billion gigabytes of information was produced in the world. By 2003, the yearly production of information had risen to 5 billion gigabytes.

Since information has become cheaper to produce, there has been a dramatic increase in the production of information. Desktop publishing, digital photography, and garage video are obvious manifestations. At the same time, since information has been cheaper to reproduce there has been a significant increase in information dissemination with virtually every newspaper, magazine, and journal publisher now offering at least some of their content via the Web.

In addition to the explosion of commercial content, the dramatically lower costs of creating and disseminating information goods has resulted in two relatively novel phenomena: the rise in user-developed content and a significant increase in illicit pirated content. Of course, both of these phenomena have historical antecedents. However, I believe they take on a special significance with digitized content.

In Shapiro and Varian [1998] we described the story of the battle between the venerable Encyclopedia Britannica and the upstart Microsoft Encarta. Subsequently, Encarta has been displaced by a brand new encyclopedia: the community-authored Wikipedia. Started in 2001, this web-based encyclopedia offers over a million articles in English of quality comparable to long established reference works. ${ }^{2}$

Open source software is another form of user-developed content that has had significant economic impacts. (Shapiro and Varian [2004]) Another important phenomenon has been the rise of blogs, with Technorati, a blog search engine, reporting that it has indexed over 50 million blogs. (See

\footnotetext{
${ }^{2}$ See http://en.wikipedia.org/wiki/Wikipedia: About.
} 


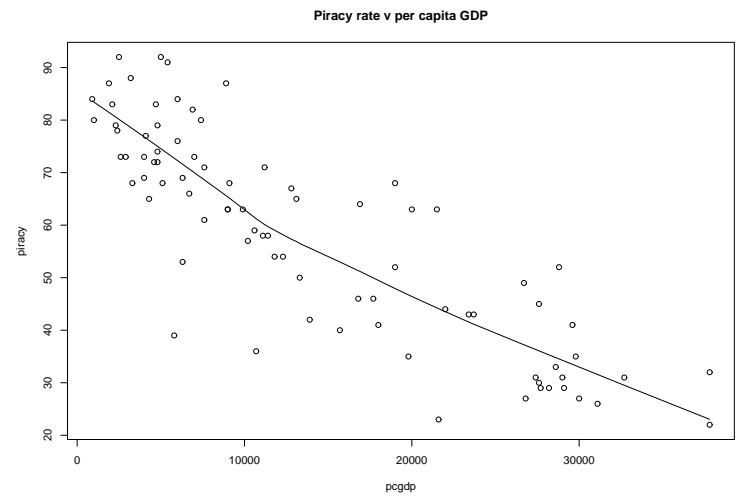

Figure 1: Per-capita income $\mathrm{v}$ fraction of software that is pirated for various countries. Source: Business Software Alliance and the CIA World Fact Book. (Business Software Alliance [2004] and CIA [2004])

http://www.sifry.com/alerts/archives/000436.html.)

But along with this dramatic increase in production of new content, the in the cost of information reproduction has also led to a significant amount of illicit use of copyrighted materials. Illicit use, of course, is notoriously hard to measure. Liebowitz [2005], after a careful review of the evidence, suggest that the number of illegal downloads of music are about the same magnitude as purchases of music, roughly 3 billion songs per month in 2000.

Illicit copying is widespread in developing nations. Figure 1, taken from Varian [2005a] plots the estimated fraction of software that is pirated against per capita GDP. Of course, it is not particularly surprising that less developed countries find it tempting to free ride on more developed ones. The biggest copyright pirate in the world in 1891 was the United States. ${ }^{3}$

\footnotetext{
${ }^{3}$ See Warner [1999] and Varian [2005a].
} 


\section{Term extensions}

The initial term of copyright in the United States was for 14 years. It was extended to 28 years in 1831, with a 28 year renewal option added in 1909. In 1962 the term became 47 years, and 67 years in 1978. In 1967 the term was defined as the life of the author plus fifty years, or 75 years for "works for hire." The 1998 Sonny Bono Copyright Term Extension Act lengthened this term to the life of the author plus 70 years for individuals and 75-95 years for works for hire. ${ }^{4}$

One might ask whether 95 years should really be considered as consistent as a "limited time" as described by the U.S. Constitution. In Akerlof et al. [2002], seventeen economists (of which I was one) argued that the economic benefits of the 20 year extension were trivial. A simple present value calculation shows that at a $7 \%$ rate of interest, the value of a twenty-year extension is about 0.33 percent of the present value of the first 80 years of copyright protection.

This is a very conservative calculation, as it assumes a constant flow of returns from the intellectual property. In reality there are very few works that produce such a royalty stream. Fewer than 11 percent of the copyrights registered between 1883 and 1964 were renewed after 28 years. Furthermore of the 10,027 books published in 1930, only 174 were still in print in 2001 . (Landes and Posner [2003], p.212)

But if the extension was worth so little to the owners of copyright, why would anyone bother to extend the term? The answer is that the copyright term was extended retroactively so that existing works that were near expiration were given a new lease on life.

Retroactive copyright extensions in this way makes no economic sense, since what matters for the authors are the incentives present at the time the work is created. If there were no such grandfathering it is unlikely that

\footnotetext{
${ }^{4}$ http://en.wikipedia.org/wiki/Sonny_Bono_Copyright_Term_Extension_Act
} 
anyone would have bothered to ask for copyright extensions.

Despite these economic arguments, the U.S. Supreme Court found in a 7-2 decision that the Sony Bono Copyright Extension Act was constitutional, citing the copyright acts of 1790, 1831, 1909, and 1976 as precedent for retroactive extensions. The Court reiterated a lower court's argument that a retroactive term extension can satisfy the "limited times" provision in the Constitution clause, as long as the extension itself is limited instead of perpetual.

It seems clear that the original intent of the authors of the U.S. Constitution was that a "limited time" meant something like 14 years since that was the prevailing term for copyright. The position adopted by the Court might be characterized as follows: 14 years is a limited time and a limited time plus one year is a limited time therefore any finite time period is a limited time.

As recently as 1960 the copyright term was 28 years; it is now on the order of a century. Given the reliance on precedent by the Supreme Court, there is no reason why it could not be extended again.

\section{Implications of extended term of copyright}

Since the copyright term is now so long and there is no requirement of registration, it can be very difficult to locate copyright holders. This has been true for many years, but the problem is likely to get worse in the future unless there are significant legal and/or technological changes.

Since copyright registration and renewals are not required for a great many works there is no easy way to find current owners. George [2002] indicates that in their attempt to locate publishers to seek permission to digitize their works, 22 percent could not be found. Written material is the easy case. Imagine the difficulties in trying to find the copyright owners for old photographs. The transactions costs of such rights clearance can be prohibitive. 
One approach to the problem would be to require registration in order to receive a copyright. Unfortunately, various international treaties make such a change the law very difficult. At least one author has proposed restricting statutory damages to, say, $\$ 1$, unless a work is registered. This is an interesting work-around, but such a change in the law is unlikely.

Landes and Posner [2003] argue the case for a renewable copyright term. As they point out, a system for renewals would require the government to maintain an up-to-date copyright registry and would provide significant incentives for copyright holders to keep their registration material up-to-date.

\section{Orphan works}

Recognizing the substantial costs in clearing rights, in 2005 the U.S. Copyright Office requested comments on what to do about "orphan works," that is, works for which the rights holders could not be found. ${ }^{5}$ During 2005 they studied the issue and subsequently released a report describing their analysis and proposed legislation to deal with the problem. See their web page at http:/www. copyright.gov/orphan for detailed descriptions and access to the report and a summary.

The proposed legislation requires that a user perform a "reasonably diligent search" in order to locate a rights holder. If the user could prove that he had conducted such a search and was unable to identify the rights holder, should such a rights holder subsequently appear he would be limited in terms of remedies for copyright infringement.

The report indicates that standards for a reasonably diligent search must be applied on a case-by-case basis. Relevant considerations would include

- The amount of identifying information on the copy of the work itself, such as the author's name, copyright notice, or title;

\footnotetext{
${ }^{5}$ http://www . copyright.gov/fedreg/2005/70fr3739.html
} 
- Whether the work had been made available to the public;

- The age of the work, or the dates on which it was created and made available to the public;

- Whether information about the work can be found in publicly available records, such as the Copyright Office records or other resources;

- Whether the author is still alive.

The report also requires that users of orphan works clearly attribute the authorship of works for which he has not received explicit permission, insofar as possible.

If a user can prove that he had conducted a reasonably diligent search and that he complied with the attribution requirement, then if a copyright owner steps forth and identifies himself, the proposed amendment would limit the remedies available to the owner in two ways.

First, monetary relief would be limited to "reasonable compensation for use." In particular, if the use was non-commercial, there would be no monetary relief, as long as the infringer ceased use upon notice.

Second, the proposed legislation puts restrictions on injunctive relief. In particular, when an orphan work has been incorporated into derivative work that also "includes significant expression of the user," an injunction could not be used to stop the publication of such a work, though there would still be an obligation of reasonable compensation. Furthermore, in other cases "the court must account for and accommodate any reliance interest of the user that might be harmed by the injunction."

Essentially, the proposed legislation is weakening the rights of the copyright holder in cases where a potential user of the work has made a diligent effort to locate the holder. 


\section{Economic analysis of orphan works}

In order to explicate some of the economic forces at work in this area, let us consider a simple model of search for a rights holder.

Let $e_{b}$ be the search effort exerted by a buyer and $e_{s}$ be the search effort exerted by a seller of some good, in this case a copyrighted work. The probability that the buyer and seller will locate each other is denoted by $P\left(e_{b}, e_{s}\right)$, where this function is assumed to be increasing in both arguments. The value to the buyer of acquiring a license to use the work is denoted by $v$ and we use $p$ to denote the price paid to seller. The marginal cost of effort to each party is denoted by $c_{b}$ and $c_{s}$ respectively.

The buyer's goal is to maximize

$$
\text { payoff to buyer }=P\left(e_{b}, e_{s}\right)(v-p)-c_{b} e_{b},
$$

while the seller's goal is to maximize

$$
\text { payoff to seller }=P\left(e_{b}, e_{s}\right) p-c_{s} e_{s} .
$$

Societal net benefits are given by

$$
\text { social welfare }=W\left(e_{b}, e_{s}\right)=P\left(e_{b}, e_{s}\right) v-c_{b} e_{b}-c_{s} e_{s} .
$$

There is an obvious externality in that the probability of being found depends on the efforts exerted by both parties, whereas each party is concerned only with its own costs and benefits.

Then the first order conditions for the Nash equilibrium are:

$$
\begin{aligned}
\frac{\partial P\left(\hat{e}_{b}, \hat{e}_{s}\right)}{\partial e_{b}}(v-p) & =c_{b} \\
\frac{\partial P\left(\hat{e}_{b}, \hat{e}_{s}\right)}{\partial e_{s}} p & =c_{s}
\end{aligned}
$$


while the first-order conditions for the social optimum are

$$
\begin{aligned}
& \frac{\partial P\left(e_{b}^{*}, e_{s}^{*}\right)}{\partial e_{b}} v=c_{b} \\
& \frac{\partial P\left(e_{b}^{*}, e_{s}^{*}\right)}{\partial e_{s}} v=c_{s}
\end{aligned}
$$

We first note the rather obvious point that too little effort will be exerted in the Nash equilibrium. Differentiate $W\left(e_{b}, e_{s}\right)$ with respect to $e_{b}$ and $e_{s}$ and note that since $v>p$ in a voluntary exchange we have:

$$
\begin{aligned}
& \frac{\partial W\left(\hat{e}_{b}, \hat{e}_{s}\right)}{\partial e_{b}}=\frac{\partial P\left(\hat{e}_{b}, \hat{e}_{s}\right)}{\partial e_{b}} v-c_{b}=\frac{\partial P\left(\hat{e}_{b}, \hat{e}_{s}\right)}{\partial e_{b}} p>0 \\
& \frac{\partial W\left(\hat{e}_{b}, \hat{e}_{s}\right)}{\partial e_{b}}=\frac{\partial P\left(\hat{e}_{b}, \hat{e}_{s}\right)}{\partial e_{s}} v-c_{s}>\frac{\partial P\left(\hat{e}_{b}, \hat{e}_{s}\right)}{\partial e_{s}} p-c_{s}=0 .
\end{aligned}
$$

Hence social welfare is increasing in the effort of both parties at the Nash equilibrium.

The incentives here directly analogous to the standard tort analysis in the law and economics literature. In accident law, people exert effort to avoid accidents. Since neither party faces the total costs of the accident, each takes inadequate care. In the search problem each party exerts effort to find a trading partner, but neither party gains the full benefits the trade. Hence each party exerts inadequate effort.

In tort law, the solution to the externality problem is liability: the courts set a due care standard and if the parties meet this standard they escape liability. If they do not meet the standard they have to pay the costs of the accident; see Shavell [1987] for a seminal treatment. Here the solution is similar: the courts set a "diligent search" standard which is the level of effort and provide appropriate incentives for buyers and sellers to internalize the search costs. 


\section{Hold-up}

In the model sketched above, the seller and buyer search for each other and, if they are found, a transaction takes place. How is the price of that transaction determined?

One possibility would be that the seller sets a take-it-or-leave-it price. With full information, the seller would choose the monopoly price $v$ and extract all of the surplus from the transaction. Since, in general, the buyer will have to exert some effort to find the seller, this results in the buyer receiving negative surplus overall. Recognizing this, the buyers finds it futile to engage in search.

This is, of course, the classic hold-up problem. The effort exerted by the buyer is a sunk cost; there is no reason for the seller to take it into account in setting a price. But the result is that the buyer can never recover its costs of search, leading it to avoiding even trying.

This outcome could occur even in a reasonably competitive environment, as along as all buyers are identical and information about price dispersion is not available. In each case the seller would set the price to be equal to $v$. Since each buyer would expect that all other sellers do the same, there would be no gains from further search. This is reminiscent of Diamond [1871]'s classic search model, which also resulted in the monopoly price.

Suppose, instead, that there is some variation in the buyers' values. The result would not then be so stark, but it would still be the case that sellers would attempt to exploit some of their monopoly power due to the lack of information and sequential nature of the search problem. The fact that they would do so ex post would discourage search ex ante.

These considerations suggest that a posted price regime would be much more efficient than a negotiated price. If the buyers could determine the licensing fee ex ante they would be more willing to expend the search effort.

One example of such is a system is the mechanical reproduction fee model used in the United States. This system, dating back to the days of the player 
piano, mandates a set fee payable to the songwriter for the right to make a mechanical reproduction of a work. The fee is set by Congress every ten years and is currently 6.95 cents per song or 1.3 cents per minute per copy. The fee may be paid directly to the rights holder or to the Harry Fox Agency, a clearing house in New York. This agency accepts online payments at their web site, www.harryfox.com.

The attraction of a fixed fee is that it reduces the monopoly pricing problem and the hold-up problem that would inevitably arise in an environment where search is costly. On the other hand, a one-size-fits-all model may not be flexible enough to work across all media and all circumstances.

\section{A simple model of diligent search}

Let us specialize the model introduced earlier to the case of discrete effort levels where the buyer and seller can either take appropriate levels of care or not. Let these be denoted by $e_{b}^{*}$ and $e_{s}^{*}$, respectively. A natural interpretation is that $e_{s}^{*}$ is the cost of registering a work (effort + financial), and $e_{b}^{*}$ is the cost of effort of searching the registry.

The model is considerably simplified if we assume that the registry is completely effective so that $P\left(e_{b}^{*}, e_{s}^{*}\right)=1$ and $P\left(e_{b}^{*}, 0\right)=P\left(0, e_{s}^{*}\right)=P(0,0)=$ 0 . Hence if both parties use the registry, the item is always found and it is never found if either party fails to use the registry.

We say it is efficient to transact if

$$
v-e_{b}^{*}-e_{s}^{*} \geq 0 .
$$

We say it is mutually profitable to transact is there exists a $\bar{p}$ such that

$$
\begin{aligned}
v-e_{b}^{*}-\bar{p} & \geq 0 \\
\bar{p}-e_{s}^{*} & \geq 0 .
\end{aligned}
$$


The following fact is perhaps obvious but worth stating.

Fact 1 (Efficiency $<=>$ profitability.) It is efficient to transact if and only if it is mutually profitable to transact.

Proof. Rearranging (8), the condition for efficiency,

$$
v-e_{b}^{*} \geq e_{s}^{*} \geq 0 .
$$

Hence we can find a $\bar{p}$ such that

$$
v-e_{b}^{*} \geq \bar{p} \geq e_{s}^{*} \geq 0,
$$

and it is easy to see that this choice of $\bar{p}$ satisfies (9)-(10).

Conversely, suppose that it is not efficient to transact, so that

$$
v-e_{b}^{*}-e_{s}^{*}<0,
$$

but that a $\bar{p}$ exists that satisfies (9)-(10). Adding (9)-(10) yields equation (8), a contradiction. []

This observation shows that all we need to do is to ensure that the payoffs to the buyers are sellers are non-positive if they don't meet the appropriate levels of diligence.

This is easy for the buyer. If he doesn't use the (possibly) copyrighted work at all, he receive utility 0 . On the other hand, he make take a chance and use the copyrighted work anyway. In this case, we suppose that there is a probability $\pi$ that the owner steps forward in which case the buyer must pay damages $\hat{p}$. Hence his expected payment from not exercising diligent search is $v-\pi \hat{p}$. Setting $\hat{p} \geq v / \pi$ will ensure that he is better off exercising diligent search rather than taking a chance. Normally we would think that $\pi$ would be rather low, so $\hat{p}$ may have to be rather high to ensure appropriate incentives. In fact statutory damages for copyright infringement are on the 
order of $\$ 150,000$ per incident, which should satisfy the relevant condition unless $\pi$ is very small.

Turning to the seller, we have already seen that if the seller achieve a zero payoff if $e_{s}=0$, we are ensured an efficient outcome. This is, indeed, the only case that guarantees efficiency.

Fact 2 (Positive payoffs to seller are inefficient) If the seller fails to meet the minimal effort standard and still receives a positive payoff, then there are some values of $v$ for which it is efficient to contract, but there are no mutually profitable transactions.

Proof. Suppose per absurdum, that it is mutually profitable to transact and yet the seller receives a positive payout:

$$
\begin{aligned}
v-e_{b}^{*}-\bar{p} & \geq 0 \\
\bar{p}-e_{s}^{*} & =D>0 .
\end{aligned}
$$

Consider the case where $v=e_{b}^{*}$. Then (14) implies that $\bar{p}=0$ and (15) implies that $-e_{s}^{*}=D>0$, which is impossible. []

In other words, if the seller receives a positive payment and the buyer is only marginally interested (given the transactions costs) the payment the buyer would be willing to make might not be adequate to ensure that the seller would be willing to exert the minimal level of effort (i.e., be willing to register).

Note that as usual in incentive problems, the expected fine incurred by the buyer would not necessarily be equal to the compensation paid to the seller. Indeed, if they were, the seller could easily face an "incentive to be injured." That is, they would deliberately fail to register in the hope that if their intellectual property rights were infringed, then they would be able to collect the (large) statutory damages and even injunctive relief.

The proposed legislation wisely avoids this problem through limitations on monetary and injunctive release. (See section 4 of Orphan Works Report 
entitled "Limitations on remedies", pp. 11-13.) In particular, monetary relief would be limited to "reasonable compensation." Although they do not precisely define this term, one might interpret this as being similar to the license fee that would have been agreed upon if the buyer and seller had found each other. In our stylized model, the expected damages would then be on the order of $\pi \bar{p}$. As we have seen, this would lead to some inefficiency, but if $\pi \bar{p}$ is small, the efficiency loss would also be small.

\section{A centralized copyright registry}

As we have hinted, a very natural interpretation of "effort" would be the effort required to register or look up a work in a centralized database. We also mentioned that there is currently no legal requirement to register copyrighted works and changing this would require renegotiating various international treaties.

However, it may well happen that language in the proposed legislation such as "diligent search" and "reasonable compensation" may lead to enhanced functionality and increased use of existing copyright registries. Furthermore, new registries that contained licensing fee information could be created. They Copyright Clearance Center does this for printed information, but registries for other media could created along the same lines.

As we have seen, the seller must have an incentive to enter and update its information in a copyright registry and and the buyer must have an incentive to look there. Since the effort cost would be essentially zero and the probability of finding each other would be approximately 1, we could expect that a copyright registry along with a "diligent search" requirement would come close to solving the problems outlined above. Indeed, several observers have called for such a centralized copyright registry including Landes and Posner [2003], Patry and Posner [2004], Varian [2005b]. 


\section{Mass digitization}

The final topic that we will discuss is various mass digitization efforts such as the Google Library Project. For a more detailed analysis, see Varian [2006].

Recently, Google has contracted with several libraries to digitize the works in their collections. This is done at Google's expense using special technology it developed for the project. The total size of the corpus is about 25 to 30 million books.

The Google Library Project should not be confused with the Google Publisher Partner program, in which publishers voluntarily submit books for Google to scan into their catalog.

In the Publisher Partner Program, searchers can see about 4 pages of the book to assist them in deciding whether or not to purchase it. In the Google Library program, searchers can see only a few lines of the text to ascertain how relevant it may be to their query. See Figure 2 for an example.

The Publisher Partner program is opt-in: publishers specifically have to submit their books to be scanned. The Library program is opt-out: publishers (or other rights holders) can send Google a note asking them to remove the book from their index.

In September 2004, the Authors Guild, which has about 8,000 authors as members, filed a complaint against Google claiming that the Library Project violated copyright. ${ }^{6}$ The Association of American Publishers filed a similar lawsuit on October 19, 2005, on behalf of five of its members, The McGrawHill Companies, Pearson Education, Penguin Group (USA), Simon \& Schuster and John Wiley \& Sons.

The primary objection of the publishers is that Google should not be allowed to copy their works without prior agreement. According to the complaint, Google is "engaging in massive copyright infringement."

Google argues that its is simply making "fair use" of the works. Fur-

\footnotetext{
${ }^{6}$ http://www. boingboing.net/images/AuthorsGuildGoogleComplaint1.pdf
} 


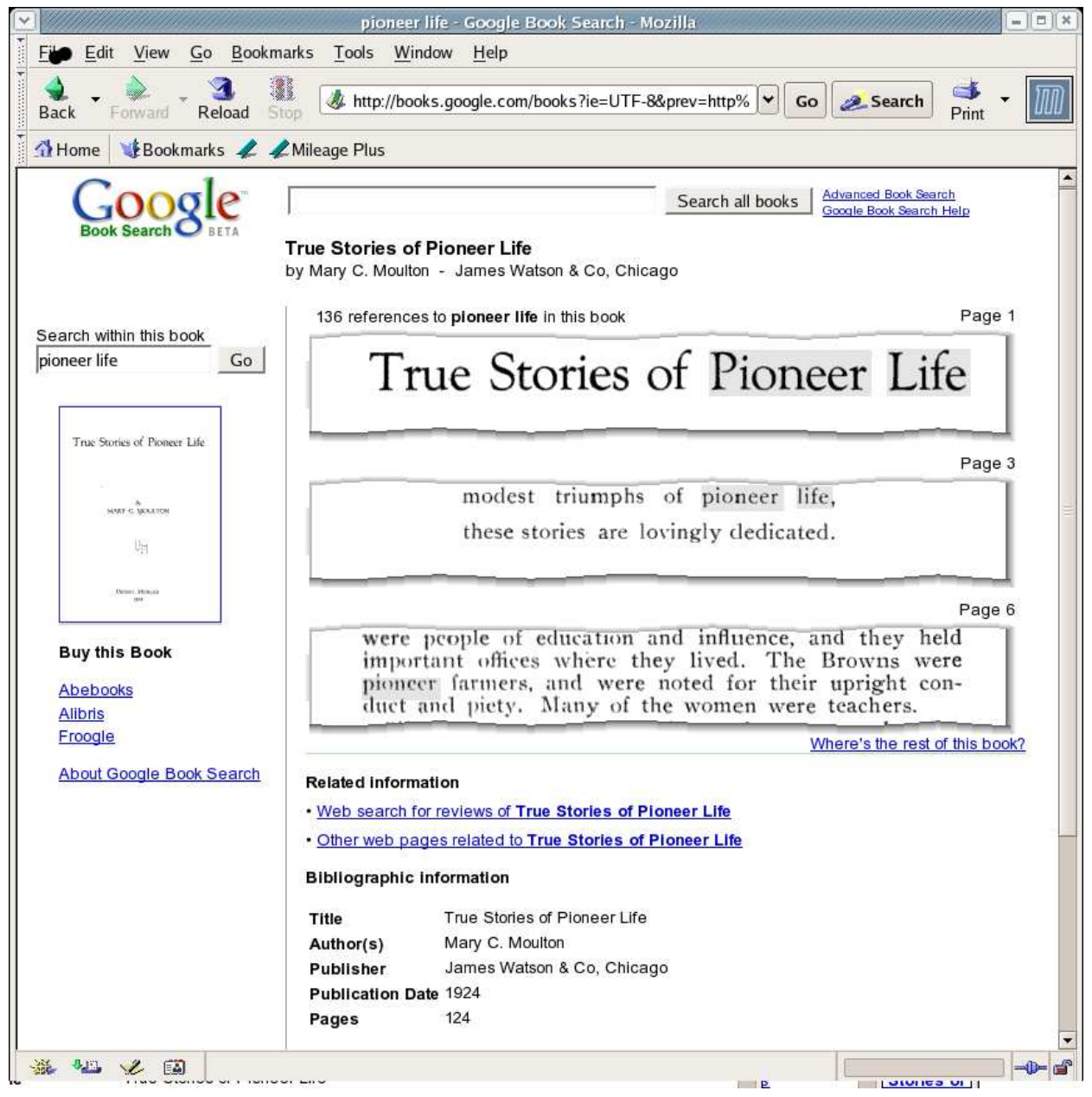

Figure 2: Screen shot from Google Library. 
thermore, any publisher can opt-out of the program simply be sending the relevant information to Google. The interesting economic questions revolve around the interpretation of the fair use doctrine and the opt-out versus opt-in model.

\subsection{Opt-in v opt-out}

As we have noted earlier, locating the legitimate rights holder of a work can be very costly. This problem has become much worse now that the effective copyright term has been extended to well over 100 years.

Approximately 65 percent of works that Google intends to scan are outof-print. There is very little incentive for rights-holder of an out-of-print work to maintain current information in a registry such as that maintained by the Copyright Office or the Copyright Clearance Center.

The publishers are well aware that it is very costly to identify rights holders.Tony Sanfilippo, marketing and sales director for Penn State University Press, says

"The compilation of that list in and of itself would take a lot of resources. We've been publishing for 50 years, University of Pennsylvania has been publishing for more than 100 years, Johns Hopkins University Press has been publishing for more than 125 years. The amount of scholarship involved is enormous, involving hundreds of thousands of books just from university presses. Why should it be the responsibility of the university press community to do that work?"

However, from the viewpoint of transactions cost economics, the question should be which party has the lower cost of identifying rights holdersGoogle or the university press? There is virtually zero cost to the publishers

\footnotetext{
${ }^{7}$ http://pda.physorg.com/lofi-news-google-copyright-books_7646.html
} 
in identifying works published since the advent of ISBN numbers in 1967, which is the most relevant category in terms of likely query volume.

The orphan works problem is bad for works published since 1967, but before that date the problem is virtually insurmountable in some cases. How can one possibly find the rights holder of a work that has been out-of-print for 50 years? An opt-in solution just isn't feasible.

This opt-out procedure is the same as that used by Google and other search engines on the World Wide Web. A webmaster can put a file called robots.txt in the top-level directory of his site that requests that search engines do not index some subset of the material on the site. Google, and most other legitimate search engines, scrupulously honor such requests.

In fact, it is hard to imagine how an opt-in system would work for web search. Consider how difficult it would be to make bilateral arrangements with every search engine and every web site for permission to index the material. The opt-out procedure used on the web is a sensible one since in minimizes transactions costs involved in indexing web sites.

\subsection{Fair use}

Section 107 of the U.S. Copyright Act of 1976 lays out the requirements for fair use.

Notwithstanding the provisions of sections 106 and 106A, the fair use of a copyrighted work, including such use by reproduction in copies or phonorecords or by any other means specified in that section, for purposes such as criticism, comment, news reporting, teaching (including multiple copies for classroom use), scholarship, or research, is not an infringement of copyright. In determining whether the use made of a work in any particular case is a fair use the factors to be considered shall include

- The purpose and character of the use, including whether 
such use is of a commercial nature or is for nonprofit educational purposes;

- The nature of the copyrighted work;

- The amount and substantiality of the portion used in relation to the copyrighted work as a whole; and

- The effect of the use upon the potential market for or value of the copyrighted work.

Band [2005, 2006] and Varian [2006] analyze the fair use factors in the Google Library Project on a point-by-point bases. Here our primary concern is the last issue: the effect on the market.

Here, it is eminently clear that assisting users in finding works relevant to their interests enhances the value of their work. The display of a two or three line snippet of text surrounding is trivial with respect to "amount and substantiality" of the work and not discourage purchase of the work except in very rare and unlikely circumstances.

Induces, directories and catalogs are complements for the works then index, not substitutes. So why would the publishers not welcome a technology to make their works more accessible?

The simple answer is that the publishers want to retain complete control of the works. Of course the publishers should be happy if Google creates a souped up online library catalog for free. But it would be even better if Google paid the publishers for the right to do this ... at least from the publishers point of view.

There is no question that they have the right to control cases where the work is copied in order to create a substantially competing work; the question is whether rights holders can control copying of the work for substantially different uses, particularly those that enhance the value of the work in question. 
Here, we have to look at the relevant transactions costs. If copyright is narrowly interpreted so that the rights holder can control virtually all uses of the works in question and they have no strong incentives to be easily found, then there would be very little incentive for innovators to build systems (such as search engines) that enhance the value of copyrighted works.

True, the owners of copyrighted works gain in aggregate when such systems are available, but the incentives for any individual rights holder could be small.

Furthermore, when one looks at various catalogs produced in other industries, the most successful ones appear to be those managed by third parties. Look at Books in Print, TV Guide and other TV directories, Amazon's book catalog, and library catalogs all are which are produced by third parties. So far as I know, the content owners do not receive payment from the guide producer. In fact, the most typical model is for the content owner to pay to be included in a directory, as in yellow page directories.

There are many cases, such as American Airline's Sabre system for listing airplane schedules where the fact that it was controlled by one of the industry participants led to substantial disputes concerning antitrust issues of equal treatment.

If we want to have a robust and competitive market for directories, indices and catalogs, I believe that it will be necessary to minimize the transactions costs associated with prior rights negotiations. Of course there will eventually be cases where some compiler steps over the line of fair use by using excessively large extracts or creates works that are substantial competitors for the works in question. However, the courts will be able to reign in such behavior when it arises.

The rapid growth of content, particularly digital content, is unlikely to abate any time soon. Putting arbitrary barriers in front of those trying to navigate this sea of information would be hugely counterproductive. 


\section{References}

George A. Akerlof, Kenneth J. Arrow, and Timothy F. Bresnahan. Amicus Curiae brief in the case of Eldred v Ashcroft. Technical Report 01618, Harvard Law School, 2002. http://eon. law.harvard.edu/openlaw/ eldredvashcroft/supct/amici/economis\%ts.pdf.

Jonathan Band. The Google Print Library Project: A copyright analysis. E-Commerce Law \& Policy, August 2005. URL http://www . policybandwidth.com/doc/googleprint.pdf.

Jonathan Band. Copyright owners v. the Google Library Project. 17 Entertainment Law Review, 21, January 2006. URL http://www. policybandwidth.com/doc/googleprint-EntLaw.pdf.

Business Software Alliance. Global software piracy study. Technical report, Business Software Alliance, 2004. http://www.bsa.org/globalstudy/ contact/.

CIA. CIA World Fact Book. CIA, 2004. www.cia.gov/cia/publications/ factbook/.

Peter Diamond. A model of price adjustment. Journal of Economic Theory, pages $156-168,1871$.

Carole A. George. Exploring the feasibility of seeking copyright permission. Technical report, Carnegie-Mellon Libraries, 2002. URL http: //www.library.cmu/edu/Libraries/FeasibilityStudy.ppt.

William M. Landes and Richard A. Posner. The Economic Structure of Intellectual Property Law. Harvard University Press, 2003.

Stan J. Liebowitz. File-sharing: Creative destruction or just plain destruction. Technical report, University of Texas at Dallas, 2005. http: //www . utdallas. edu/ ${ }^{\sim}$ liebowit/intprop/destruction4.pdf. 
Peter Lyman and Hal R. Varian. How much information. Technical report, UC Berkeley, 2000. http://www.sims.berkeley.edu:8000/research/ projects/how-much-info.

Peter Lyman and Hal R. Varian. How much information. Technical report, UC Berkeley, 2003. http://www.sims.berkeley.edu:8000/research/ projects/how-much-info-2003.

William D. Nordhaus. The progress of computing. Technical report, Yale University, 2002. http://nordhaus.econ.yale.edu/prog_030402_all. pdf.

William F. Patry and Richard Posner. Fair use and statutory reform in the wake of Eldred. California Law Review, 1(1), 2004. www.bepress.com/ cgi/viewcontent.cgi?article=1003\&context=ev.

Carl Shapiro and Hal R. Varian. Information Rules: A Strategic Guide to the Network Economy. Harvard Business School Press, 1998.

Carl Shapiro and Hal R. Varian. Linux adoption and the public sector. Technical report, UC Berkeley, 2004. URL http://www.sims.berkeley . edu/ 〜hal/Papers/2004/linux-adoption-in-the-pub\%lic-sector.pdf.

Steven Shavell. Economic Analysis of Accident Law. Harvard University Press, Cambridge, MA, 1987.

Hal R. Varian. Copying and copyright. Journal of Economic Perspectives, 19(2):121-138, 2005a.

Hal R. Varian. Universal access to information. Communications of the ACM, 48(10):65-66, 2005b.

Hal R. Varian. The Google Library Project. Technical report, UC Berkeley, 2006. URL http://www.sims.berkeley.edu/〜hal/Papers/2006/ google-library.pdf. 
Julian Warner. Information society or cash nexus? A study of the United States as copyright haven. Journal of the American Society for Information Science, 50(5):461-470, April 1999.

Richard Watt. The past and future of the economics of copyright. Review of Economic Research on Copyright Issues, 1:1-11, 2004. 